Revista Iberoamericana, Vol. LXX, Núms. 208-209, Julio-Diciembre 2004, 677-695

\title{
PRODUÇÃO LITERÁRIA E PROJETOS POLÍTICO-CULTURAIS EM REVISTAS DE SÃO PAULO E DA CIDADE DO MÉXICO, NOS ANOS 1910 E 1920
}

\author{
POR \\ Regina Aída Crespo \\ Universidad Nacional Autónoma de México
}

INTRODUÇÃO

Em 1910, a Cidade do México foi palco de festas suntuosas pelo Centenário da Independência. $\mathrm{O}$ ano funcionou simultaneamente como chave de ouro para os 34 anos da ditadura de Porfirio Díaz e como porta de entrada para mais de uma década de instabilidade política e transformações estruturais. Durante os anos 10, esse longo período de incertezas, a capital mexicana passou por uma série de mudanças que se refletiram em sua vida cultural e política. Centro inconteste da vida nacional, a cidade seria, inicialmente, pólo de sangrentas disputas pelo poder e, posteriormente, já na década seguinte, pólo irradiador de políticas sociais e culturais para o conjunto do país.

No Brasil do mesmo período, vivia-se a chamada República Velha. Apesar de sua aparente modorra, as transformações pelas quais o país passou durante esse período foram importantes e demandam, inegavelmente, que ele seja reconsiderado naquilo que lhe era próprio. Durante esses anos, São Paulo passou a exercer um papel particularmente relevante, devido à preponderância da economia cafeeira, geradora de um processo acelerado de urbanização, industrialização e modernização econômica. A busca pela hegemonia política empreendida pelas elites paulistas fez da sua capital um centro influente e representou o incremento de sua criação literária, cultural e artística. O mito do bandeirante e a imagem de São Paulo como a locomotiva do país configurariam e legitimariam paulatinamente o domínio paulista.

A análise comparativa da criação literária e intelectual veiculada em revistas que circularam nas cidades de São Paulo e do México, nos anos 1910 e 1920, oferece elementos valiosos para compreender esse período de inquestionável efervescência cultural e política. As duas cidades compartilharam tal efervescência e foram, ainda que por razões diversas, centros estratégicos na produção de projetos culturais, que as revistas literárias e culturais do momento ajudaram a criar e difundir.

De início, uma questão importante que se deve resolver relaciona-se aos critérios mais convenientes para selecionar revistas que circularam em um período que, tanto no México como no Brasil, caracterizou-se por uma série de rupturas, instabilidades e transformações em termos artísticos, intelectuais e políticos. Um período no qual a própria definição das publicações periódicas como literárias ou culturais era em certo sentido difusa. 
No caso do México, a magnífica coleção fac-similar Revistas literarias mexicanas modernas (1979-1986) oferece ao leitor um rico panorama das publicações do período, funcionando como uma fonte de consulta fundamental para o estudo do tema. ${ }^{1}$ Por seu intermédio, podemos conhecer revistas literárias de curta duração (um ou dois números) como Gladios (1916) e La Nave (1916); revistas estudantis como Nosotros (1912-1914) e San-ev-ank (1918), em que despontariam futuros talentos literários, e revistas produzidas por escritores e artistas reconhecidos, como a semanal Pegaso (1917), na qual conviviam literatura, informação jornalística, crítica de espetáculos, esportes e entretenimento. Também podemos confrontar projetos culturais distintos, como o das revistas México Moderno (1920-1923) e El Maestro (1921-1923). México Moderno, a primeira revista literária que apareceria depois da Revolução Mexicana agrupava os escritores mais importantes do momento. Olimpicamente afastada dos temas do contexto político-social mexicano, a revista se dedicava exclusivamente à chamada alta cultura, em oposição a $E l$ Maestro, revista institucional editada pela Secretaría de Educación Pública, que, com um especial ecletismo, propunha um projeto de resgate cultural de amplo alcance social, sustentado em um esquema de ampla distribuição, de caráter gratuito para a população de baixa renda.

Curiosamente, a disponibilidade desse riquíssimo material para consulta não tem despertado o interesse de muitos críticos e historiadores literários e culturais. Produziramse alguns índices críticos e estudos preliminares de revistas literárias, como as fundamentais Revista Azul, de Gutiérrez Nájera (Díaz y Alejo y Prado Velázquez 1968), e Revista Moderna, de Valenzuela (Valdés 1967) e acerca de algumas das revistas publicadas na referida coleção fac-similar (Franco 1981; Sheridan 1988). No entanto, até o momento, não se consolidou uma linha de pesquisa específica e sistematicamente destinada ao estudo de tão importante material. ${ }^{2}$

No caso brasileiro, temos uma situação inversa à do México. A inexistência, no Brasil, de uma coleção fac-similar com os alcances da mexicana dificulta, obviamente, a divulgação e a consulta das revistas, principalmente das que circularam nas primeiras décadas do século xx, cujos originais estão dispersos em vários arquivos e bibliotecas. É preciso admitir que, à exceção da edição fac-similar de algumas publicações como Estética (1974); A Revista (1978), Revista de Antropofagia (1976) e Klaxon (1976), as revistas

\footnotetext{
${ }^{1}$ A coleção reproduz, em vários volumes, o conteúdo completo de 40 revistas que circularam entre 1906 e 1965, acompanhadas de breves apresentações. Cabe esclarecer que, ao longo do texto, as revistas serão citadas de acordo com os dados de sua publicação original e não com os da edição facsimilar.

${ }^{2}$ Uma contribuição importante para o estudo das revistas literárias mexicanas dos anos 10 e 20 encontra-se no trabalho de Sheridan (1985) sobre o grupo “Contemporáneos”. De maneira cronológica, o autor acompanha o percurso dos poetas deste que ficaria conhecido como "o grupo sem grupo" e, nessa trajetória, analisa a linha editorial e o projeto cultural e político de revistas nas quais tais poetas colaboraram, como San-ev-ank, México Moderno e El Maestro. Como material de referência sobre as revistas literárias do México, é preciso destacar o importante ciclo de conferências, promovido pelo Instituto Nacional de Bellas Artes, em 1962. Tais conferências preparadas por críticos, jornalistas e escritores, muitos dos quais haviam participado do corpo de redação das próprias revistas analisadas, foram publicadas em dois volumes, em 1963 e 1964.
} 
culturais e literárias brasileiras não têm recebido a mesma atenção editorial que as mexicanas. No entanto, não se pode deixar de reconhecer que os estudos que se vêm realizando de forma relativamente constante acerca de tais materiais cumpre a função de aproximá-los dos leitores em geral e do público especializado em particular. Nesse sentido, vale a pena mencionar os trabalhos de teor monográfico produzidos nas décadas de 1970 e 80 sobre revistas pré-modernistas e modernistas como, por exemplo, Kosmos (Dimas 1983), Revista do Brasil (Ikeda 1975), Klaxon e terra roxa e outras terras (Lara 1972) e Novíssima (Guelfi 1987). Alguns estudos mais recentes, realizados com uma perspectiva mais cultural e histórica que especificamente literária (Crespo 1990; Luca 1999), contribuem, junto com os anteriores, para a compreensão da criação literária, ideológica e cultural veiculada pelas revistas, bem como do contexto político e ideológico em que elas circularam.

O interessante panorama que se vislumbra a partir dos materiais originais e dos estudos mencionados pode conduzir à elaboração de uma interessante análise comparativa. No entanto, há alguns elementos que vale a pena examinar antes de realizá-la. Voltemos à nossa questão inicial: que revistas selecionar entre as que circularam em um período tão instável, quando a própria definição das revistas literárias ou culturais era tênue?

Não devemos perder de vista que, durante as décadas de 1910 e 1920, tanto no México como no Brasil, vivia-se um processo editorial ainda incipiente. Por um lado, o público leitor era muito reduzido, o que não favorecia a produção e a distribuição de livros em larga escala. Por outro lado, a imprensa ocupava um lugar importante nesse horizonte de poucos leitores, satisfazendo o desejo de informação e cultura de muitos deles. Os jornais de caráter político-informativo normalmente mantinham páginas e seções dedicadas à literatura, à crítica literária e de artes plásticas. Ademais, vários seguiam a tradição oriunda do século anterior de publicar romances em forma de folhetim. Esses espaços cumpriam uma tarefa importante na difusão da criação literária e crítica, representando para os escritores, poetas e críticos a oportunidade de atingir mais leitores.

Em ambos os países, veículos tão ou mais importantes que os jornais como espaços de difusão cultural eram as chamadas revistas ilustradas (as quais, curiosamente, ainda conformam um terreno praticamente virgem para os pesquisadores). Ao cumprir a tríplice função de informar, instruir e divertir, tais revistas conseguiam conquistar um público cativo, geralmente de elite, funcionando, elas também, como um canal importante para a difusão da produção cultural, literária e artística do momento.

Em um contexto em que, tanto no México como no Brasil, a maioria das revistas estritamente literárias ou culturais costumava ter vida breve, a criação literária e intelectual requeria o apoio de meios de difusão complementares. Não se pode ignorar que, enquanto tais revistas circulavam de maneira geralmente precária e errática, em poucos números que se perdiam entre um público leitor especializado e restrito, as revistas ilustradas possuíam um campo de circulação representativamente maior. Isso lhes dava uma grande visibilidade social, cultural e política e uma capacidade substantiva de influência junto ao público, com a possibilidade de interferir na própria formação do seu gosto e, eventualmnte, de difundir com maior êxito novas correntes literárias, artísticas e ideológicas.

Ora, se pretendemos estudar algumas revistas para procurar entender e refletir sobre a efervescência cultural e política das cidades de São Paulo e do México, nas décadas de 
1910 e 20, vale a pena evitar os critérios de definição estritos para a sua eleição. Ampliemos os horizontes da análise, com a incorporação de revistas que, independentemente de uma definição rigorosa como culturais ou literárias, possuíam, no momento em que circularam, um projeto cultural explícito ou implícito, e uma postura própria e representativa dos debates que se desenvolviam acerca do contexto político e da criação intelectual e literária. Como veremos, durante as décadas de 1910 e 1920, tais revistas foram testemunhas de um processo significativo de mudanças nos planos político, econômico e cultural, e foram porta-vozes de alguns setores sociais interessados em participar ativamente de tal processo. Assim, não só é possível vê-las a partir de uma perspectiva especificamente cultural e literária, como também do ponto de vista político e ideológico, considerandoas arenas de reflexão e influência.

Para este exercício breve e panorâmico de comparação, foram selecionadas seis publicações. Frutos de um amplo processo de criação intelectual e estética, elas merecem ser estudadas como parte ativa e definidora do contexto social, cultural e político de que fizeram parte.

A longeva e tradicional Revista de Revistas, publicação semanal ilustrada fundada por Luis Rojas, e a aparentemente fútil e ingênua A Cigarra, publicação quinzenal do paulista Gelásio Pimenta, possuíam muito em comum. Vencendo praticamente incólumes vários períodos de instabilidade e mudanças sociais, tanto a revista mexicana como a brasileira conseguiram conquistar fatias relativamente amplas e diversificadas de público. Ambas ofereciam a esse público, além de artigos de opinião, notícias, literatura e curiosidades científicas e históricas, muitas fotos e ilustrações requintadas, fofocas e propaganda. Essa mescla entre cultura e entretenimento, temperada com um forte apoio à política oficial, consolidaria uma corrente importante na mídia dos dois países. ${ }^{3}$

Como uma espécie de publicação híbrida, entre o que se poderia definir como revista literária, ilustrada e gazeta política, com um amplo espaço destinado ao humor, $O$ Pirralho, a primeira revista do futuro modernista Oswald de Andrade, aproxima-se de certa maneira da polêmica e áspera Multicolor. A revista mexicana, fundada pelo jornalista político espanhol Mario Vitoria, mesclou irreverência, caricatura, crítica política, sátira e

\footnotetext{
${ }^{3}$ A Revista de Revistas circulou de 1910 a 1972. Nesses 62 anos, teve muitos proprietários e editores. Apesar de se definir como apolítica, apoiou enfaticamente o governo de Porfirio Díaz. Até 1924, apesar de algumas mudanças em sua linha editorial, foi uma revista declarada ou implicitamente governista (à exceção da curta presidência de Francisco Madero, a quem fez velada oposição). Infelizmente, sua característica mais interessante se perdeu: a reprodução, em espanhol, de artigos de periódicos nacionais e estrangeiros (basicamente estadunidenses e europeus). Essa política, que durou praticamente toda a década de 10 e deixou de existir iniciados os anos 20, dava-lhe um lugar particularmente importante no panorama local, e um caráter cosmopolita, que a diferenciava das competidoras. A Cigarra, por sua vez, surgiu em 1914. Até 1924, a revista foi editada por Gelásio Pimenta, seu fundador-proprietário. Durante esses dez anos, manteve uma postura política e socialmente conservadora e um caráter essencialmente triunfalista Em 1934, alguns anos depois da morte de Pimenta, A Cigarra foi vendida ao empresário e jornalista Assis Chateaubriand e passou a ser publicada no Rio.
} 
maledicência, em doses nem sempre justas e proporcionais, para retratar um dos períodos mais conflituosos da Revolução Mexicana. ${ }^{4}$

Finalmente, El Maestro e a Revista do Brasil -revistas que conquistaram um lugar oficial na história cultural, literária e política de seus respectivos países-compartilharam algumas preocupações de teor cultural, estético e ideológico. Seus editores eram escritores e intelectuais que, no caso da primeira publicação, estavam atrelados ao Estado e, no caso da segunda, buscavam influenciá-lo, ou pelo menos dialogar com ele. Ambas as revistas deixaram de lado o mundanismo, o entretenimento e a sátira política veiculados pelas publicações anteriormente mencionadas, para dedicar-se plenamente à tarefa de formular e difundir um projeto de cultura, pensado em termos nacionais. ${ }^{5}$

\section{As REVISTAS E O CONTEXTO POLítICO-CULTURAL}

Se partimos do pressuposto de que, na dinâmica do campo cultural, revistas como as mencionadas conformaram um lugar singular de criação e difusão cultural e literária, uma questão que vale a pena analisar se refere a saber até que ponto elas se mantiveram acordes, ou não, com os parâmetros culturais, literários e artísticos hegemônicos do momento.

Nesse contexto, o tema da tradição é fundamental. Pensemos, tanto no caso do México como no do Brasil, no estabelecimento e na consolidação de parâmetros culturais relacionados ao que Raymond Williams define como "tradição seletiva”, isto é, uma versão intencionalmente seletiva de um passado configurador e de um presente préconfigurado, que funciona como um elemento poderosamente operativo dentro do processo de definição e identificação cultural e social (137). A questão é interessante, pois as revistas mexicanas e brasileiras mencionadas compartilharam, em certo sentido, um mesmo "passado significativo", no dizer de Williams (138). No entanto, os argumentos

\footnotetext{
${ }^{4}$ O Pirralho circulou, semanalmente, de 1911 a 1915 e, a partir de então, quinzenalmente, até 1917. A revista manteve uma linha de crítica irreverente a alguns personagens do contexto político nacional, além de sempre opinar com certa independência sobre temas e acontecimentos do momento. No entanto, $O$ Pirralho nunca deixou de se comportar como uma revista "mundana", a par dos interesses do público de elite ao qual finalmente se dirigia. Multicolor circulou, também semanalmente, de maio de 1911 a julho de 1914, quando fechou suas portas em meio à crise da presidência do militar golpista Victoriano Huerta, a quem havia apoiado e que passou à história mexicana como "el usurpador". Multicolor sustentou uma campanha inclemente contra o candidato e, depois, presidente Francisco Madero, e acabou desaparecendo junto com Victoriano Huerta, quando este fugiu do país, em julho de 1914.

${ }^{5}$ El Maestro. Revista de Cultura Nacional constou de 17 números e circulou de 1921 a 1923. Foi criada por iniciativa de José Vasconcelos, reitor da Universidade Nacional de junho de 1920 a outubro de 1921, e ministro da educação, de outubro de 1921 a julho de 1924. De abril a setembro de 1921, a revista foi editada pela universidade e, a partir de outubro, pela SEP - Secretaría de Educación Pública. A Revista do Brasil, publicação mensal, foi fundada em 1916 por um grupo de intelectuais paulistas reunidos em torno da figura de Júlio de Mesquita, dono do jornal O Estado de S. Paulo. De 1918 a 1925, a revista pertenceu ao escritor e empresário Monteiro Lobato, quem consolidou sua orientação reflexiva, crítica e nacionalista e ampliou o espaço dedicado pela publicação à literatura brasileira.
} 
que manipularam, a partir desse passado, para a ratificação cultural e histórica do momento em que lhes tocou viver nem sempre foram os mesmos.

Conhecer as revistas e analisá-las, em seus vínculos com o contexto em que circularam, significa acompanhar sua trajetória e a luta -silenciosa ou veemente, vitoriosa ou não- que desenvolveram pela consolidação de um espaço próprio no terreno políticocultural. Os grupos representados em cada uma delas buscaram não apenas atrair determinadas parcelas do público, como conquistar legitimidade cultural e política suficiente para difundir e, eventualmente, implantar suas idéias e projetos.

Para refletir sobre as revistas escolhidas e o lugar que ocuparam no México e no Brasil dos anos 10 e 20, devemos procurar saber se atuaram, e de que maneira, como criadoras ou defensoras de uma determinada tradição cultural; se conquistaram autoridade e legitimidade suficientes no campo cultural, para atuar como “instituições”; se buscaram ou não criar novos paradigmas estéticos ou culturais; se atuaram ou não como a expressão, no dizer do próprio Williams, de “formações” intelectuais e artísticas.

REVOLUÇÃO SOCIAL E CONSERVADORISMO LITERÁRIO?

Com referência ao México, é interessante confrontar dois elementos. Por um lado, o ritmo acelerado das transformações político-ideológicas experimentadas pela população em geral, e pelas elites intelectuais em particular, a partir da eclosão da Revolução Mexicana e do fim do Porfiriato (com o conseqüente desmantelamento do positivismo dominante e da hegemonia intelectual francesa). E, por outro lado, a manutenção, tanto nas publicações explicitamente literárias como em jornais e em revistas ilustradas, de um estilo literário intimamente vinculado aos parâmetros do modernismo hispano-americano, estilo aparentemente afinado com um momento político e social já ultrapassado pelo novo contexto.

Curiosamente, os conflitos e choques sangrentos que assolaram a capital mexicana ao longo da década de 1910, ajudando a redesenhar o tabuleiro político e social não só da cidade como de todo o país, não chegaram a influenciar a produção de seus poetas e ficcionistas, destinada à publicação em revistas e jornais. Ou, pelo menos, não impediram que o lugar destinado às “belas letras” na maioria dessas publicações continuasse ocupado pelos tradicionais nomes consagrados e por alguns de seus epígonos.

Assim, a Revista de Revistas destinaria muitas páginas de sua seção "Página Literária” e, depois, "Letras y arte” à difusão de sonetos, poemas em prosa e pequenas crônicas de Rubén Darío, Gutiérrez Nájera, Salvador Díaz Mirón, Amado Nervo, Enrique González Martínez, Luis Urbina, José Juan Tablada e de alguns poetas e escritores mais jovens como Efrén Rebolledo, Max Henríquez Ureña e Alfonso Reyes. Rodó, Ingenieros, Leopoldo Lugones e outros mexicanos e latino-americanos menos famosos faziam-se acompanhar de Anatole France, Edgar Allan Poe, Remy de Gourmont, John Keats, Eça de Queiroz, Baudelaire e Víctor Hugo. A revista também publicaria romances em forma de folhetim, com títulos eloqüentes como "La cruz de la estepa”, de uma desconhecida Dorothea Gerard.

Enquanto isso, reservaria parte significativa do espaço de suas seções de artigos e notícias à defesa da volta à normalidade política e social do país e à crítica ao movimento 
revolucionário. ${ }^{6}$ Pode-se dizer que, em publicações como a Revistas de Revistas, o lugar da arte manter-se-ia protegido das atribulações - que muitos, equivocadamente, acreditavam passageiras -de um grande e promissor país acossado por uma turba enlouquecida, conduzida por líderes irresponsáveis.

Num contexto como esse, o espaço reservado à discussão e às divergências culturais e literárias teria que ser postergado. Por exemplo, o debate entre as correntes defensoras de uma arte engajada e comprometida com a cultura nacional e as que defendiam uma arte elaborada e alheia à política (e, por isso, alienada, segundo muitos de seus antagonistas) só teria lugar na década seguinte. Apenas nos anos 20, quando a situação política já havia chegado a uma relativa estabilidade, a necessidade de um diagnóstico cultural para o México acabou por vir à tona. Procurar compreender um país desigual e contraditório e definir-lhe um projeto cultural abrangente e factível passaria, então, a ser uma preocupação freqüente para muitos artistas e intelectuais. Refletir sobre as características da literatura nacional também. ${ }^{7}$

Antes, porém, nos seus chamados “anos duros”, a Revolução foi considerada por muitos deles e pela grande maioria dos meios de comunicação como a eclosão de uma barbárie atávica que a “verdadeira civilização” (concebida em termos da velha estabilidade porfiriana) necessitava vencer. Ora, a revista Multicolor foi mestra em tratar a Revolução, suas várias facções em luta, e os seus principais personagens, especialmente Francisco Madero e Emiliano Zapata, a partir desse pressuposto, traduzido literariamente em paródias e em poemas humorísticos, acompanhados de charges com textos maledicentes e de duplo sentido e de pequenos relatos cômicos coalhados de preconceitos.

Nesse sentido, é possível afirmar que uma das razões para resgatar Multicolor dessa espécie de "limbo" em que se mantém recolhida até hoje está exatamente no interesse em

\footnotetext{
${ }^{6}$ Ver, por exemplo, “El reinado de la barbarie” (12 ene. 1913):2, artigo anônimo sobre o ataque de zapatistas a uma fábrica, em que se comenta que “desde que la revolución de 1910 echó abajo al régimen porfiriano, las hordas que se ampararon bajo las banderas de esa misma revolución con el único propósito de robar, de asesinar y de cometer toda clase de atentados, han asolado el territorio de la República, sin que el Gobierno haya logrado extinguirlas”.

${ }^{7}$ A Revista de Revistas incentivaria tal reflexão, publicando o artigo "La moderna literatura mexicana”, de Julio Jiménez Rueda (12 e 19 feb. 1922). Nele, o crítico apresentava um panorama da poesia mexicana, a partir do Modernismo, no qual enumerava os poetas mais representativos e os mais promissores. Nesse momento, Jiménez Rueda estava otimista com os rumos da criação literária nacional: “Nunca como ahora la República está en mejor aptitud para producir grandes poetas, interesantes dramaturgos, amenos cuentistas. El pensamiento, puesto en los grandes dolores del país, ha hecho que vayan los artistas al pueblo, que busquen sus tradiciones, que estudien sus costumbres”. Em 1925, o mesmo crítico, nada otimista, iniciaria uma longa polêmica no jornal El Universal Ilustrado, com "El afeminamiento en la literatura mexicana”, artigo em que destacava a artificialidade da vida intelectual mexicana, a dificuldade dos escritores em deixar sua torre de marfim e a inexistência de uma obra literária capaz de expressar "las agitaciones del pueblo en todo ese periodo de cruenta guerra civil [...] el pueblo [que] ha arrastrado su miseria ante nosotros sin merecer tan siquiera un breve instante de contemplación” (Schneider 163). Tal polêmica teve como mérito tornar conhecida a chamada "Novela de la Revolución” e em trazer à discussão a existência ou não de uma literatura emancipada das formas do passado. Sobre o tema, consultar Schneider e Díaz Arciniegas (1989).
} 
estudar a maneira como trabalhou discursiva e literariamente toda a sua irreverência. O próprio "lugar" da literatura na revista merece uma análise acurada. Ao contrário das publicações tradicionais, Multicolor não possuía uma seção especificamente destinada à literatura. A revista bordava os fatos do momento, opinava sobre personagens da política e analisava temas candentes como, por exemplo, as relações do México com os Estados Unidos, por meio de textos reflexivos e analíticos, mas principalmente utilizando registros literários. ${ }^{8}$ Tal procedimento, poderíamos dizer, ajudava a aproximar a literatura da vida real, retirando-a da tradicional redoma de cristal onde as revistas tradicionais costumavam mantê-la protegida.

Uma análise, ainda que panorâmica, dos 164 números da publicação comprova que os redatores de Multicolor conseguiram criar e manter uma linguagem inusitada dentro do panorama normalmente formal e cerimonioso da imprensa mexicana. De fato, sem ultrapassar as barreiras de um moralismo de classe excludente e retrógrado, e de um conservadorismo político que muitas vezes raiava pelo puro oportunismo, a revista construiu um retrato irreverente do México revolucionário, diferente das visões soturnas e pessimistas sobre a Revolução, veiculadas pela imprensa da época. Ao mesmo tempo, seus redatores (escudados por pseudônimos perfeitamente adaptados ao "espírito" da revista, como Fray Locuras; E. L. Quinto; C. Nizo, Chupatintas e Atila) souberam incorporar a seus textos elementos do cotidiano político e social do país, construindo um quadro sócio-cultural rico e dinâmico. Prova disso são as crônicas do também colaborador de Revista de Revistas J. Rafael Rubio (aqui, sob o pseudônimo Rejúpiter), reunidas na seção "Semana Cómica”, capazes de fazer com que Multicolor, cujos próprios editores definiam como "frívola”, e que, ao que parece, nunca pretenderam que fosse mais que uma folha política e de circunstância, recebesse o status de revista literária por parte de críticos consagrados como Francisco Monterde (1962 118).

No início dos anos 20, período conhecido como pós-revolucionário, a antiga oposição “civilização e barbárie”, implícita nas avaliações da Revolução Mexicana, tão claras nos artigos de Revista de Revistas e tão irônica e comicamente tratadas em Multicolor, continuaria vigente, atenuada por conotações eventualmente mais paternalistas, porém não menos rígidas.

\footnotetext{
${ }^{8}$ Ver, por exemplo, “Todo en calma” (29 jun. 1911), pequena crônica que questiona a capacidade de liderança de Madero e critica a instabilidade política do país. Ver, também, Atila. "San Emiliano Zapata” (9 nov. 1911), poema rimado, em octossílabos, que ironiza Zapata. A “elegância”, a alma generosa, a linguagem correta e até a "santidade" do personagem, fazem o poeta sugerir que ele seja incorporado ao almanaque dos santos católicos. Vale a pena conhecer "Prácticamente terminados", de E. L. Quinto (23 ene. 1913), longo poema em dodecassílabos, no qual o “autor” critica a situação do país, a debilidade de Madero e a violência de Zapata. O fecho do poema - "Que viviré implorando divina gracia/Para que pronto acabe la democracia” - ilustra significativamente a linha políticoideológica de Multicolor. Finalmente, a crônica "Semana política”, de Un Familiar (30 jul.1914), no último número de Multicolor. Ao analisar ironicamente as pugnas entre as facções revolucionárias, o autor chega a tratar o futuro presidente, Venustiano Carranza, por “don Venus”. A revista, que já ridicularizara Madero, adotava aqui, ainda que atenuadamente, uma irreverência inusitada para o cerimonialismo tradicional da imprensa diante das autoridades políticas.
} 
Talvez um dos efeitos mais importantes da Revolução Mexicana tenha sido o de colocar em evidência a existência de um México subterrâneo, que 34 anos de ditadura porfiriana haviam conseguido ocultar. Uma população atacada pela miséria e pela desigualdade e a decomposição do país em regiões dominadas por exércitos e caudilhos em pugna fizeram brotar uma fúria de reivindicações, com uma violência que exigia soluções, que reclamava a criação de novas políticas sociais.

Ora, especificamente com relação ao âmbito cultural, a proposta de redimir essa enorme população, considerada pelas elites do país como cultural e economicamente atrasada, e até então mantida completamente à margem dos benefícios da cultura hegemônica -ocidental, de matriz hispânica- envolveria os intelectuais reunidos na revista El Maestro em um eloqüente projeto de integração e padronização cultural. Coerente com seus propósitos formativos, El Maestro difundia notícias nacionais e internacionais, curiosidades científicas e conhecimentos práticos, ao lado de textos de autores gregos, europeus, hispano-americanos e mexicanos consagrados.

A seção de literatura contava com a presença de nomes como Tolstói, Gorki, Sor Juana, Gabriela Mistral, Alfonsina Storni, os modernistas Darío, González Martínez, Gutiérrez Nájera e Santos Chocano. Entre os colaboradores mexicanos, também se encontravam os reconhecidos José Juan Tablada, Julio Torri e López Velarde, além dos jovens promissores (e colaboradores de Vasconcelos) Carlos Pellicer, Jaime Torres Bodet e José Gorostiza.

El Maestro abriu suas portas a jovens escritores como estes que, embora possam ser classificados dentro de uma categoria não exatamente elogiosa, a dos "poetas-funcionários" (assumindo, na casa dos vinte anos, tarefas de Estado excessivamente importantes para sua nula experiência), em termos específicos de sua produção literária, anos mais tarde, tiveram um papel de destaque. Vinculados ao grupo Contemporáneos buscariam uma maior cosmopolitização da literatura e das artes mexicanas, em oposição ao nacionalismo cultural e artístico que, durante toda a década de 1930 e, em grande parte como decorrência dos movimentos de valorização nacional estimulados pela própria política vasconcelista da década anterior, foi hegemônico no país. Observemos, porém, que suas colaborações à revista ainda estão imbuídas do forte ibero-americanismo e do messianismo cultural de Vasconcelos, e seus poemas, à exceção da leveza informal e da jovialidade criadora de Pellicer, ainda estão carregados de formalismos modernistas. Sua presença em El Maestro não representou nenhuma ruptura nos cânones literários e culturais hegemônicos no momento, nem na linha político-ideológica da publicação. ${ }^{9}$

Ao falar sobre a linha político-ideológica de El Maestro, é inevitável concluir que a revista deve ser entendida exatamente como parte do projeto cultural institucional elaborado e conduzido por José Vasconcelos. Este forte defensor do caráter hispânico da civilização mexicana propôs-se a missão titânica de "regenerar" o país e, por isso, sua

${ }^{9}$ Quanto aos textos: Gorostiza. "Recordando a los humildes”. I 1 (abr.-sep. 1921):31-32; Torres Bodet.” 'El Emilio’ de Juan Jacobo Rousseau”. I 1 (abr.-sep. 1921):33-36; Pellicer. “A los estudiantes mexicanos". I 1 (abr.-sep. 1921):37. Quanto aos poemas: Pellicer. "El Sol! El Sol! El Sol!” I 2 (abr.-sep. 1921):203; Torres Bodet. “Una mujer”. I 2 (abr.-sep. 1921):205; Gorostiza. "Balada de la luz sumisa”. I 4 (abr.-sep. 1921):431-432. 
primeira tarefa foi mobilizar a população alfabetizada, principalmente a classe média, a participar de uma campanha nacional de alfabetização (Crespo 1997 86). Depois, como segundo passo, decidiu incentivar o hábito da leitura entre a população, facilitando o seu contato com os livros, mediante a publicação de títulos pela própria Secretaria de Educação Pública e a fundação de bibliotecas por todo o país. ${ }^{10}$

A publicação de El Maestro se insere indubitavelmente num amplo projeto de formação de leitores, incorporados à cultura ocidental de matriz hispânica. Essa preocupação ideológico-formativa se comprova não só com a veiculação de grandes pensadores da chamada cultura ocidental (principalmente os já mencionados filósofos gregos e escritores europeus), mas principalmente com o fato de que o elemento indígena -considerado uma presença viva na realidade mexicana- não encontrava lugar nas páginas de El Maestro. É certo que a capa de alguns de seus números levava ilustrações indígenas estilizadas. Além disso, as grandes civilizações pré-hispânicas receberam sua atenção e foram analisadas arqueológica ou historicamente. ${ }^{11}$ No entanto, tal perspectiva fazia das culturas indígenas, quando muito, uma tradição (“seletiva”) a reverenciar. E, de acordo com ela, era possível deduzir que os indígenas se confinariam num passado glorioso, porém morto.

Quanto aos herdeiros desse passado -uma enorme faixa da população política e economicamente marginalizada - a revista indiretamente indicava que deveriam ser incorporados à sociedade nacional, por meio da educação e da cultura. Uma análise do conteúdo de El Maestro indica que a opção ideológica de seus editores em atrair a população para a cultura e as artes não levava em conta a própria diversidade cultural característica do México como um valor a preservar, mas sim como um problema a resolver.

Nesse contexto, é inevitável observar que El Maestro possuía uma forte dose de paternalismo, que pode ser ilustrado com o desejo externado por Vasconcelos de que a revista difundisse conhecimentos úteis e todas as idéias nobres e proveitosas. Afinal, como diria, "la verdadera luz no tiene precio, y luz será lo que procuraremos difundir, ofreciéndola, dándola aún a los que no la pidan” (“Un llamado cordial”. I 1 (abr.-sep. 1921): 7). Por isso, o então reitor da Universidade Nacional abria o primeiro número da publicação, conclamando todos os professores do país para que colaborassem nessa que deveriam considerar como sua revista:

\footnotetext{
${ }^{10} \mathrm{O}$ polêmico projeto editorial de Vasconcelos incluía publicar A Ilíada, A Odisséia, Ésquilo, Eurípedes, Platão, Plutarco, Plotino, Goethe, Tagore e Romain Rolland, além dos Evangelhos (1993 I 47), em tiragens médias de 25.000 exemplares (Fell 488). Vasconcelos recebeu muitas críticas ao editar filósofos gregos num país em que se falavam mais de 50 línguas e em que uma parte significativa da população (cerca de 10\%) não falava, muito menos pensava o mundo no espanhol nacionalizador. Além dos filósofos, a SEP editou livros de leitura para o ensino primário e manuais técnicos e artísticos, destinados à educação e sensibilização do povo. Normalmente, os livros eram editados em grandes quantidades e vendidos abaixo do custo, ou distribuídos gratuitamente (Crespo 106).

${ }^{11}$ Ver, por exemplo, Mena. "Nueva orientación arqueológica e histórica”. III 2 (abr. 19221923):154-166; e Hyde. “Antigüedad del hombre en el Valle de México”. II 4-5 (oct. 1921-mar. 1922):366-387.
} 
escribiremos para los muchos, mas con el propósito constante de elevarlos, y no nos preguntaremos qué es lo que quieren las multitudes, sino qué es lo que más les conviene, para que ellas mismas encuentren el camino de su redención. I 1 (abr.-sep. 1921): 6.

Paternalismo e um forte voluntarismo foram características básicas não apenas de $E l$ Maestro, como da maioria das iniciativas que configuraram o plano educativo e cultural que o Estado mexicano pós-revolucionário colocou em prática e que José Vasconcelos concebia como “missão”, inspirada, não por acaso, na ação catequética dos primeiros missionários católicos que chegaram ao México (Crespo 85). O propósito da revista El Maestro, muito mais que funcionar como uma arena de produção de conhecimento, era atuar como meio de divulgação. Por isso, a distribuição gratuita e em larga escala. Por isso, a mescla de artigos, ensaios e poemas, a princípio díspares, como, por exemplo, sobre a importância da higiene de olhos e ouvidos; sobre os adubos mais baratos; sobre o latifúndio, visto como o verdadeiro inimigo da pequena propriedade e do bem-estar geral do país; sobre a história do México, sinteticamente apresentada, das antigas civilizações pré-colombianas à Revolução. ${ }^{12}$ Por isso, o estímulo ao nacionalismo e ao iberoamericanismo (um dos projetos políticos mais caros a Vasconcelos, que pretendia aproximar o México do universo latino-americano, tanto política como culturalmente). A publicação de poemas de López Velarde, Santos Chocano e Gabriela Mistral, entre outros, e de vários artigos de difusão sobre aspectos históricos e geográficos de países latinoamericanos, como Brasil, Argentina, Venezuela, Chile, etc., fizeram da revista, indubitavelmente, uma voz singular com relação ao tema. ${ }^{13}$

BELLE-ÉPOQUE E NOVOS TEMPOS

O caso do México e de sua capital configura um contraste interessante com o que ocorria no Brasil e, em especial, na cidade de São Paulo. Não se pode ignorar que os brasileiros não viveram nenhum movimento social similar à Revolução Mexicana. Ora, no âmbito da produção cultural e literária, a ausência de um conflito de tal magnitude poderia significar a manutenção de uma atmosfera de celebração permanente (ou, se quisermos, de entediante marasmo). Para críticos como Alfredo Bosi, a máxima de Afrânio Peixoto dava a tônica da época:

\footnotetext{
A literatura é como o sorriso da sociedade. Quando ela é feliz, a sociedade, o espírito se lhe compraz nas artes e, na arte literária com ficção e com poesias, as mais graciosas expressões da imaginação. Se há apreensão ou sofrimento, o espírito se concentra, grave, preocupado, e então, histórias, ensaios morais e científicos, sociológicos e políticos, sãolhe a preferência imposta pela utilidade imediata. (220)

${ }^{12}$ Respectivamente, II 4-5 (oct. 1921-mar. 1922):455-457; III 1 (abr. 1922-1923):88-99; Caloca II 4-5 (oct. 1921-mar. 1922):436-439; Ramos Pedrueza I 1 (abr.-sep. 1921):123-130; I 3 (abr.-sep. 1921):235-242; I 4 (abr.-sep. 1921):341-348).

${ }^{13}$ Respectivamente, López Velarde. "La suave patria”. I 3 (abr.-sep. 1921):311-314, Santos Chocano. “La campaña de Dolores”. I 5-6 (abr.-sep. 1921):623-625, Mistral. “El grito”. II 4-5 (oct.1921-mar.1922): 339-340.
} 
Nesse sentido, poderíamos deduzir que, sem apreensão nem sofrimento, as artes e a literatura ganhariam um forte estímulo e um caráter de inconteste exaltação. O lugar da literatura estaria resguardado e a separação entre arte e política também. Essa visão é patente na revista A Cigarra que, coerente com o próprio nome, anunciava em seu primeiro número o seu principal objetivo: oferecer ao leitores o verão a cada quinzena. A Cigarra não se propunha ser útil, mas sim agradável, presenteando os leitores com as "indispensáveis inutilidades que constituem o ornato e o encanto da existência” (“Crônica” 6 mar 1914). Entre elas a revista classificava a arte como a suprema e oferecia ao seu público muitos contos, poemas e uma série de crônicas literárias, muitas delas refletindo sobre temas como as mudanças de estação climática e a intensa vida social e cultural da cidade de São Paulo. ${ }^{14}$

Entre seus escritores colaboradores estavam, na prosa, os indefectíveis Coelho Neto e Cornélio Pires, acompanhados do jovem Monteiro Lobato -que logo, logo voaria mais alto, em seu próprio veículo, a Revista do Brasil-e do irrequieto Oswald de Andrade-que já tinha uma posição de evidência, à frente de $O$ Pirralho.

Junto ao núcleo de escritores que fariam parte da história literária nacional, ou pelo menos paulista, A Cigarra possuía uma equipe de cronistas como Manuel Leiroz, que não participaria de nenhuma antologia literária, no que seria acompanhado por outros colaboradores da revista como Juliano Rey e Magalhães Torres, sem mencionar os pseudônimos Jaffa, Coroca Velha e Purcheria do Sabará. Entre os poetas, reinava Olavo Bilac, acompanhado de outros "mestres do passado" como Vicente de Carvalho e Albertina Bertha, além de vários desconhecidos (muitos deles, na realidade, estudantes de medicina ou direito, fazendo seu debut na sociedade paulista com a publicação de um soneto açucarado).

Habituados a responder ao que provavelmente definiam como o gosto médio do público em termos de criação literária, os editores de A Cigarra não costumavam aventurar-se na publicação de grandes novidades estéticas, ainda que eventualmente o fizessem. Nesse sentido, é interessante comentar que a revista publicou vários textos de Oswald de Andrade, inclusive alguns excertos da primeira versão de seu João Miramar (Crespo 1990 64) e o primeiro ato de Mon Coeur Balance, composta em francês, em parceria com Guilherme de Almeida, também colaborador eventual de A Cigarra (125). Temos, aqui, uma característica fundamental do momento, que se aplica tanto ao Brasil como ao México: o universo cultural ainda era numericamente restrito e, mais que isso, refletia uma enorme fusão entre vida social e vida literária. Assim, na cidade de São Paulo, o travesso Oswald, parte da elite econômica, partícipe de sua vida mundana e figura expressiva do mundo literário, podia ser "condescendentemente" publicado por uma revista esteticamente conservadora como A Cigarra.

${ }^{14}$ Ver, por exemplo, “Crônica” 11 maio 1915, texto que descreve a chegada do inverno e seus efeitos benéficos sobre a população chic de São Paulo; “Hora literária” 23 nov. 1916, que comemora o êxito deste evento de poesia, ao qual compareceu uma "luzida e seletíssima assistência”; "Crônica” 1 jun. 1923, que comenta com júbilo a intensa vida cultural paulistana e elogia o trabalho editorial do paulista Lobato. 
Se, na década de 1910, não parecia haver grandes dúvidas de que a literatura era "o sorriso da sociedade”, para $O$ Pirralho ela também significava riso. A revista oferecia um espaço especial para a crítica política feita com bom humor. Ao longo de seus sete anos de existência, $O$ Pirralho adotou um procedimento simultaneamente mordaz e cômica no tratamento da conduta de alguns políticos, tomados como objeto de escárnio, entre os quais o marechal Hermes da Fonseca, presidente da República, de 1910 a 1914. Fonseca foi objeto de várias crônicas humorísticas, poemas satíricos e até mesmo personagem de um encontro hilariante com dois repórteres apócrifos da revista, Pindoba e Gaudêncio. ${ }^{15}$

Além disso, $O$ Pirralho propiciava que a sensibilidade corrosiva dos redatores se transformasse em registros capazes de refletir as transformações vividas pela cidade de São Paulo como berço do desenvolvimento econômico falado com sotaque imigrante. As seções O Rigalegio, Cartas de abax'o pigues e O Birralha, xornal allemong (supostos “jornais” simuladamente autônomos, escritos por "estrangeiros” e publicados dentro de O Pirralho) confirmam o caráter perceptivo da revista frente aos novos tempos que tomavam conta da cidade. ${ }^{16}$

É interessante notar que, segundo Wilson Martins, nos anos 10, O Pirralho era muito menos inovador do que poderia parecer. ${ }^{17}$ Apesar de todas as novidades introduzidas pela publicação, se observamos a lista dos seus colaboradores literários, não podemos deixar de concordar com o crítico. Entre os poetas assíduos em O Pirralho, capitaneados por Olavo Bilac, encontraríamos Amadeu Amaral, Ricardo Gonçalves e Martins Fontes, além de "duas extraordinárias mulheres, Rafaelina de Barros e Albertina Bertha” ("Quatro anos”. 4 set. 1915). Entre os narradores, os regionalistas Alcides Maia e Monteiro Lobato, além do consagradíssimo Coelho Neto, sempre presente nas colunas literárias da época.

No entanto, na companhia de tantos escritores, por assim dizer, "tradicionais", os leitores tinham a oportunidade de deliciar-se com os textos de Cornélio Pires e,

\footnotetext{
${ }^{15}$ A narrativa da "entrevista” compõe-se da combinação de quatro elementos distintos: a paródia (por exemplo, a fala do marechal), a comicidade aliada à inverossimilhança da situação narrada, o suspense e a inserção dos pontos de vista de $O$ Pirralho no contexto do episódio narrado (Gaudêncio. "Pirralho no Palácio do Catete" 7 mar. 1914). Outro texto curioso é a "História do Brasil do Hermes" 27 dez. 1913, que transcreve a suposta versão do presidente sobre a guerra do Paraguai, cheia de comicidade e imprecisões históricas. Também vale a pena conhecer o "diário" da guerra do Contestado, firmado pelo próprio "Marechá”, em que o oportunismo e o autoritarismo dos políticos e do exército brasileiro são tratados com irreverência e ironia ("Boletim Oficial da Guerra contra os fanáticos”. Pelo Hermes. 10 out. 1914).

${ }^{16}$ Os textos, escritos por supostos imigrantes italianos e alemães eram, em primeiro lugar, o resultado de um curioso trabalho de transcrição fonético-filológica. Representaram a tentativa bem-sucedida de reproduzir na escrita o registro oral dos imigrantes, no seu esforço em falar português. Nos textos do pseudônimo Juó Bananere, algumas palavras provinham do italiano, outras passavam por um processo italianizador e se misturavam com palavras grafadas em português ou aportuguesadas, numa estruturação sintática mais aproximada da do português. Nos textos germanizados de $O$ Birralha, o procedimento era o mesmo. Ambos constituíam um registro específico - o “macarrônico"-, denominação criada pela própria revista (23 maio 1914).

${ }^{17}$ Segundo Martins (6 23), "em 1915, O Pirralho nada tinha de revolucionário, aceitando com abundância de coração os valores consagrados e a literatura oficial”.
} 
principalmente, de Juó Bananere. Tais autores traziam a fala do caipira e do imigrante ao cenário cultural do momento e, munidos de uma simpatia simultaneamente satírica acerca dessas personagens, também questionavam o parnasianismo hegemônico. Segundo Chalmers (38) autores como Pires e Bananere, responsáveis por um “regionalismo” local, paulista, também preparavam o terreno para os debates sobre arte nacional, que se incendiariam a partir da Semana de Arte Moderna de 1922.

Ora, elementos como os mencionados relativizam a afirmação de Martins e nos recordam a opinião de Brito Broca (239), para quem O Pirralho "era a revista mais típica e importante do “1900” paulistano, (...) também a mais representativa do nosso prémodernismo”. Ligada de maneira sensível às transformações sócio-culturais do momento, a revista assumia como marca própria um experimentalismo formal e uma informalidade estilística crescente, que avançava sobre o espírito belle-époque dentro de suas próprias páginas. Por isso, O Pirralho ocuparia um lugar distinto ao de A Cigarra, sua competidora pelo limitado mercado de leitores numa São Paulo que iniciava febrilmente seu caminho à modernização econômica, à hegemonia política e em busca de um papel protagonista no âmbito cultural.

É exatamente nesse sentido que a Revista do Brasil aparece como uma publicação com um papel singular. Como sabemos, este grande empreendimento da elite paulista teria um papel pioneiro como revista cultural. ${ }^{18}$ Em primeiro lugar, é importante destacar que os seus propósitos respondiam às demandas de um contexto social específico, de relativa estabilidade social e política, se comparado ao mexicano. As décadas de 1910 e 20 -ainda que a chamada "República Velha” não tenha sido um período placidamente atrelado ao passado imperial, e nem um longo preâmbulo para as mudanças representadas pela Revolução de 1930 - permitiam a elaboração de diagnósticos e a construção de projetos de cunho nacional, sem a premência de sua aplicação imediata e sem a urgência de sua utilização para enfrentar conflitos sociais nacionalmente desestabilizadores. Quando concebidos no seio das elites econômicas e políticas e inclusive culturais, tais diagnósticos e projetos culturais e políticos podiam ser considerados como parte de um diálogo entre iguais, isto é, entre representantes de setores sociais dominantes, preocupados com determinadas características nacionais, defensores de programas de reforma, mas opositores a qualquer tentativa de revolução.

Em segundo lugar, é necessário observar que a preocupação das elites intelectuais brasileiras e particularmente das paulistas com os temas nacionais recebeu um estímulo muito grande com a eclosão da Primeira Guerra Mundial, que colocou em evidência o seu próprio desconforto de pertencer a um país ao qual julgavam política e economicamente débil, fadado a um lugar obscuro no concerto da nações. Ora, nesse contexto, a tendência -que, diga-se de passagem, permanecia hegemônica desde o século anterior-à utilização

\footnotetext{
${ }^{18}$ Júlio de Mesquita concebia a Revista do Brasil como um terreno específico para a discussão de questões nacionais. A revista foi fundada como sociedade anônima, composta por 66 acionistas oriundos da elite intelectual e econômica paulista de caráter liberal: médicos, engenheiros, professores, advogados, políticos e jornalistas (Luca 42; 44-45). Nos seus primeiros dois anos, a Revista do Brasil contou com suporte ideológico, apoio técnico e ajuda financeira (em forma de propaganda) do jornal O Estado de S. Paulo.
} 
de critérios deterministas, essencialmente os de raça e meio, como ferramentas explicativas para entender o Brasil e seu povo, não incentivava entre os intelectuais a produção de análises otimistas acerca do futuro nacional.

Nesse sentido, pode-se afirmar que, desde a sua fundação, a Revista do Brasil teve como programa ajudar a construir um futuro para o Brasil, contribuindo com algo que até então não havia recebido uma atenção sistemática por parte de seus intelectuais: a reflexão sobre a história nacional e sobre a produção artística, cultural e intelectual do país. Desde o seu início, a Revista do Brasil dedicou-se à literatura, à sociologia, à geografia, à história e a temas da conjuntura política, contribuindo com diagnósticos e reflexões críticas acerca dos elementos que, a juízo de grande parte de seus colaboradores, impediam que o Brasil ocupasse o seu verdadeiro lugar no concerto das nações. Ora, nesse sentido, é importante destacar que a Revista do Brasil distinguia-se de publicações ufanistas como A Cigarra, cuja linha política sempre foi festejar os grandes feitos e vultos da história oficial e manter uma atmosfera de celebração acrítica das “riquezas e grandezas” do Brasil (“O Centenário” 1 out. 1922).

Não podemos desconsiderar o fato de que a Revista do Brasil tenha sido um empreendimento da elite liberal paulista, sem qualquer apoio oficial por parte do aparato de Estado (nem no âmbito estadual, nem no nacional). À medida que sua economia crescia, a importância política e cultural do estado de São Paulo e de sua capital se projetava. Ora, o apoio ideológico de suas próprias elites intelectuais foi fundamental tal projeção. Estas conseguiram construir, de maneira tenaz e paulatina, visões que conformariam um amplo projeto de cunho nacional para o Brasil. Fizeram-no a partir de parâmetros relacionados a uma tradição de heroísmo, associada à expansão bandeirante, que concebiam como paulista e com a qual buscaram redefinir o lugar de São Paulo, numa posição não só de liderança como de modelo a seguir pelo conjunto do país. ${ }^{19}$

Essa posição foi determinante na política editorial da Revista do Brasil, desde a sua fundação, e não mudou quando, em 1918, Lobato a comprou e a transformou numa espécie de vitrine para os livros que editava e para as campanhas culturais e sociais que estimulava”. ${ }^{20}$

${ }^{19} \mathrm{~A}$ divulgação de estudos como os de Saint Hilaire e de Alcântara Machado sobre os tempos coloniais e a vida dos bandeirantes, publicados em vários números, entre 1922 e 1923, vem comprovar a preocupação da Revista do Brasil com o resgate do papel heróico e insubstituível do estado de São Paulo na construção do país. O cultivo a esta espécie de "mito de origem" (o Brasil era o que era devido à ação dos bandeirantes) daria respaldo ao forte regionalismo que a Revista do Brasil sustentava. No contexto do mito, aos paulistas "fundadores" caberia para sempre o papel de vanguarda. Na Colônia, como os ampliadores das fronteiras. Em finais do Império e, principalmente, durante toda a República, como os construtores da riqueza e modernizadores do país (na combinação entre café, indústria e hegemonia política). Tal mito reforçaria a imagem de São Paulo como a locomotiva do progresso brasileiro - “O Progresso de São Paulo”. 2593 (set. 1923): 94-105.

${ }^{20}$ Na realidade, não se pode pensar na Revista do Brasil sem concebê-la como parte da trajetória política e intelectual de Lobato. Preocupado com as causas sociais, Lobato abriu as páginas da revista para a difusão de campanhas como as sanitárias, promovidas pelo governo paulista, e escreveu artigos em defesa de uma política de saúde pública de caráter nacional. Criou ou respaldou movimentos em prol de uma arte, de uma literatura e de uma língua nacionais, e deu espaço a 
Com relação à literatura, a Revista do Brasil constituiu uma arena de discussão interessante e, apesar de um certa ortodoxia inicial, prolífera. Lobato era dos mais aguerridos defensores de uma literatura genuinamente brasileira, de temáticas locais. Não por acaso, os colaboradores da revista eram em grande parte regionalistas como Valdomiro Silveira, Afonso Arinos, Godofredo Rangel e Léo Vaz. Já no campo da poesia, mais um vez predominaram os consagrados parnasianos Olavo Bilac, Alberto de Oliveira, Francisca Júlia e seguidores como Amadeu Amaral, Olegário Mariano, Martins Fontes. Uma mudança significativa só ocorreria a partir de 1923, quando Lobato passou a direção da revista a Paulo Prado. Então, a Revista do Brasil recebeu a colaboração sistemática de nomes ligados às novas tendências, como Guilherme de Almeida, Sérgio Milliet e Mário de Andrade.

Um estudo, ainda que superficial, do conteúdo da Revista do Brasil confirma o papel que exerceu, como um meio privilegiado para o exercício da crítica e da preocupação com temas nacionais. Porém, cabe observar que, ao contrário da mexicana El Maestro, seus editores nunca se propuseram uma função educativa e cultural de longo alcance. A Revista do Brasil não pretendia falar para muitos e, muito menos, para todos, ainda que sua intenção fosse influenciar as esferas decisórias, o que, em alguns casos, poderia resultar na implantação de projetos de amplo alcance político e social.

O projeto de construção de uma tradição que pudesse ser compartilhada pelos brasileiros -baseada na revalorização do passado e da cultura nacional-e a discussão de estratégias para o melhoramento do país, nos mais diversos âmbitos, tinham, inequivocamente, um propósito socialmente abarcador. No entanto, os grandes interlocutores da Revista do Brasil estavam entre as próprias elites.

\section{COMPARAÇÕES}

Para refletir sobre as revistas mexicanas e brasileiras de forma comparativa, retomemos a questão da "tradição", anteriormente mencionada. Encontraremos entre elas a uma série de elementos comuns. Todas atuaram como porta-vozes de grupos ideológicos, políticos e econômicos em certo sentido similares. Nenhuma delas tinha um projeto de ruptura radical das estruturas sociais e políticas nacionais, e nem mesmo no plano da criação e da experimentação artística e literária (e isso é particularmente significativo no caso do México transformado pela Revolução).

Revista de Revistas e A Cigarra compartilharam o mesmo oficialismo. Não podemos esquecer que a primeira foi, inicialmente, um veículo renovador, ao levar aos leitores mexicanos outras vozes, inclusive opostas ao seu apoio a Porfirio Díaz e à estabilidade política que este havia conseguido manter à base de censura, repressão e cooptação. No entanto, a Revista de Revistas foi abandonando essa prática para se transformar numa

numerosos intelectuais preocupados com o tema. Sua obsessão em estimular a leitura (o que explica sua obra monumental no âmbito da literatura infantil) pode ser pensada também como uma campanha social - e não apenas para estimular a venda dos livros que passou a editar. Finalmente, sua aproximação com intelectuais hispano-americanos, especialmente argentinos, representou a tentativa de estimular o intercâmbio intelectual e literário do Brasil com os vizinhos. 
revista de variedades dedicada aos gostos e expectativas de seu público leitor, surpreendendo-o raramente. Tornou-se, isso sim, uma instituição. O auto-proclamado "semanario más completo, variado e interesante de la República" dos anos 10 se transformaria, a partir dos anos 20, no "semanario nacional”. E não só porque desde o início chegava praticamente a todos os lugares do país, como porque conseguiu circular ao longo de sessenta anos, sobrevivendo a crises políticas e econômicas A Cigarra percorreu um caminho de certa maneira inverso, mas não contraditório com relação ao da revista mexicana. Inspirada pela Primeira Guerra, a “cigarra” fútil e contemplativa dos primeiros números, tornou-se guerreira: passou a lutar pelos valores da pátria e do nacionalismo e pela grandeza do Brasil, buscando construir e veicular uma imagem de incontestável esplendor para o país. A Cigarra falaria a linguagem dos vencedores. O elogio, tônica de sua linha editorial, passou a destinar-se particularmente à valorização de São Paulo, seus políticos, suas indústrias e empresários, contribuindo para o que a Revista do Brasil desenvolveria com refinado apuro: o nacionalismo paulista.

Multicolor poderia ser tomada como uma espécie de caso à parte. Veículo oficioso de grupos opostos à Revolução Mexicana (e, por isso mesmo, aferrados à velha tradição porfirista), a revista dedicou-se com afinco às tarefas de caluniar e condenar. Aproveitandose de uma liberdade de imprensa jamais conhecida durante o Porfiriato, seus redatores atacaram com crueldade Francisco Madero, exatamente quem acabou com a censura. No entanto, como já se comentou, realizaram tais tarefas com destreza e, realmente, contribuíram para "arejar” o jornalismo político com o auxílio da literatura. Os ventos da política derrubaram Multicolor e a condenaram ao esquecimento.

As semelhanças entre esta revista mexicana e a brasileira O Pirralho mantêm-se principalmente no plano da ironia e da irreverência política (ambas chegaram a publicar hilariantes "biografias de homens célebres", acompanhadas do mesmo subtítulo "à maneira de Plutarco"). No entanto, se Multicolor se apresentava como revista "frívola” e na realidade era uma gazeta política, defensora da ditadura ("los bonancibles tiempos de don Porfirio sin democracia, pero sin zapatismo” - 16 nov. 1911) e contrária às mudanças, O Pirralho se dedicava à política, mas tentava ser mais versátil. Assim, da política passava à crítica de arte, dela à poesia e, finalmente, chegava à experimentação lingüística de suas seções “estrangeiras” e suas páginas caipiras. No entanto, se $O$ Pirralho tinha percepção suficiente para abarcar as várias manifestações da diversidade, nunca deixou de ser "mundana" e, como tal, uma revista de elite. Preocupada com o seu público, raramente punha em cheque os valores tidos como inquebrantáveis. O nacionalismo era o maior deles e $O$ Pirralho sempre o respeitou. O interessante a destacar dessa publicação está exatamente nos novos rumos que indicava em suas seções mais criativas. Evidentemente, a revista nunca se constituiu como uma "instituição". Ao buscar novos paradigmas estéticos e culturais, poder-se-ia afirmar que atuou como expressão de uma formação intelectual e artística que continuaria em evidência nos anos seguintes: o modernismo.

Finalmente, falemos sobre El Maestro e Revista do Brasil. Sua presença na história cultural e literária oficial de seus respectivos países lhes proporcionaria de antemão o tão cobiçado status de instituições culturais. De fato, ambas as revistas angariaram respeito e se consolidaram como parte da tradição nacional. Mais que isso, porém, foram agentes importantes na própria construção dessa tradição. A Revista do Brasil instituiu-se como 
uma arena de discussão especificamente destinada a temas nacionais e construiu um projeto político-cultural baseado em uma leitura particular do passado e do futuro do país, em que a presença de grandes rupturas e transformações estruturais de caráter político e social nunca estiveram contempladas. A revista El Maestro, por sua vez, apesar de haver surgido em um momento de reconstrução nacional, como parte de um projeto concebido para responder a uma série de demandas sociais decorrentes da própria explosão revolucionária, tampouco colocava em xeque temas como a estratificação social e o regime político implantado no país. O voluntarismo e o paternalismo que a caracterizavam indicavam o caminho das reformas, e não da revolução.

Analisando especificamente o tema da criação e da difusão literária nessas revistas, foi possível observar a conservação de um espaço privilegiado destinado às formas literárias tradicionais - com o domínio dos preceitos modernistas no México e dos parnasianos no Brasil, nesse caso, ligeiramente atenuados por uma prosa regionalista de fundo realista, pouco ou nada experimental. A própria manutenção de tal espaço indica o caráter de certo modo “pendular” e mesmo vacilante de tais publicações, frente ao contexto cultural, literário e político em que circularam, entre a conservação e a crítica, entre a tradição e a ruptura ou, para uma vez mais recorrer a Raymond Williams, entre elementos residuais e emergentes.

Bibliografía

A Cigarra. São Paulo, 1914-1924.

A Revista [ed. fac-similar]. São Paulo: Metal Leve S. A., 1978.

Bosi, Alfredo. História concisa da literatura brasileira. 2.a ed. São Paulo: Cultrix, 1980. Broca, Brito. A vida literária no Brasil-1900. 2.a ed., revista e ampliada. Rio de Janeiro: Casa José Olympio Editora, 1960.

Chalmers, Vera. 3 Linhas e 4 Verdades-O jornalismo de Oswald de Andrade. São Paulo: Duas Cidades, 1976.

Crespo, Regina Aída. Crônicas e outros registros. Flagrantes do pré-modernismo (19111918). Campinas, 1990. Dissertação (Mestrado em Teoria Literária) - Instituto de Estudos da Linguagem, Universidade Estadual de Campinas.

Messianismos culturais: José Vasconcelos e Monteiro Lobato e seus projetos para a nação. São Paulo, 1997. Tese (Doutorado em História Social) - Faculdade de Filosofia, Letras e Ciências Humanas, Universidade de São Paulo.

Díaz Arciniegas, Víctor. Querella por la cultura “revolucionaria” (1925). México: Fondo de Cultura Económica, 1989.

Díaz y Alejo, Ana Elena y Prado Velázquez, Ernesto. Índice de la Revista Azul 1894-96 y estudio preliminar. México: UNAM, 1968.

Dimas, Antonio. Tempos eufóricos. São Paulo: Ática, 1983.

Estética [ed. fac-similar]. Rio de Janeiro: Gernasa, 1974.

Fell, Claude. Los años del águila. México: UNAM, 1989.

Franco, Lourdes. Letras de México: Gaceta literaria y artística, 1937-47. Estudio e índice. México: UNAM, 1981. 
Guelfi, Maria Lúcia F. Novíssima: estética e ideologia na década de vinte. São Paulo: USP-IEB, 1987.

Ikeda, M. A. B. Revista do Brasil - 2.a Fase. Contribuição para o estudo do modernismo brasileiro. São Paulo, 1975. 2 v. Dissertação (Mestrado em Letras) - Faculdade de Filosofia, Letras e Ciências Humanas, Universidade de São Paulo.

Klaxon. Mensário de arte moderna [ed. fac-similar]. São Paulo: Martins/Secret. Cult. Ciência e Tecnol. Est. S. Paulo, 1976.

Lara, Cecília de. Klaxon, terra roxa e outras terras: dois periódicos modernistas de São Paulo. São Paulo: IEB-USP, 1972.

Las revistas literarias de México. 2. v. México: Instituto Nacional de Bellas Artes, Depto. de Literatura, v. 1 1963, v. 21964.

Luca, Tânia Regina de. A Revista do Brasil: um diagnóstico para a (N)ação. São Paulo: Fundação UNESP Editora, 1999.

Martins, Wilson. História da inteligência brasileira. 7 v. São Paulo: Cultrix, Editora da Universidade de São Paulo, 1978. v. 6.

Monterde, Francisco. “Savia Moderna, Multicolor, Nosotros, México Moderno, La Nave, La Falange, Ulises, El Libro y el Pueblo, Antena, etcétera”. Las revistas literarias de México. México: INBA, 1963. 111-143.

Multicolor. México, 1911-1914.

O Pirralho. São Paulo, 1911-1917.

Revista de Antropofagia [ed. fac-similar]. São Paulo: Abril/Metal Leve, 1976.

Revista de Revistas. México, 1910-1924.

Revista do Brasil. São Paulo, 1916-1925.

Revistas literarias mexicanas modernas (Gladios, La Nave, Nosotros, San-ev-ank, Pegaso, México Moderno, El Maestro) [ed. facsimilar]. México: Fondo de Cultura Económica, 1979.

Schneider, Luis Mario. Ruptura y continuidad. La literatura mexicana en polémica. 2.a reimp. México: Fondo de Cultura Económica, 1986.

Sheridan, Guillermo. Los contemporáneos ayer. México: Fondo de Cultura Económica, 1985.

Índice de Contemporáneos. Revista mexicana de cultura 1928-1931. México: UNAM, 1988.

Valdés, Héctor. Índice de la Revista Moderna, arte y ciencia: 1898-1903. México: UNAM, 1967.

Vasconcelos, José. Memorias: Ulises Criollo; La Tormenta; El Desastre; El Proconsulado. 2. v. 3.a reimpresión. México: Fondo de Cultura Económica, 1993.

Williams, Raymond. Marxismo y literatura. Trad. de Pablo di Masso. Barcelona: Península, 1997. 